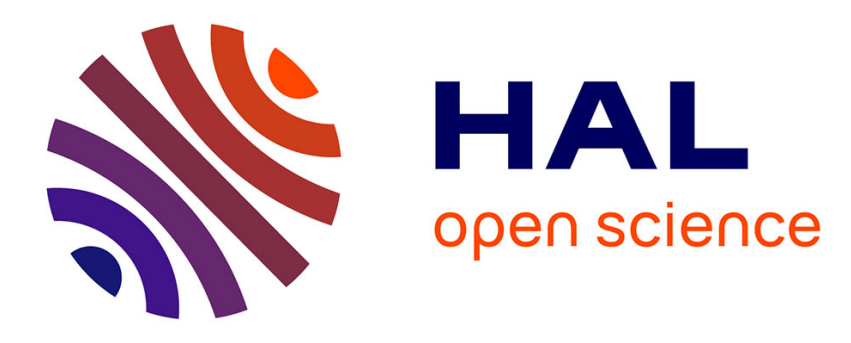

\title{
A thermo-hydraulic numerical model to study spot laser welding
}

Marc Medale, Charline Xhaard, Rémy Fabbro

\section{To cite this version:}

Marc Medale, Charline Xhaard, Rémy Fabbro. A thermo-hydraulic numerical model to study spot laser welding. 8e Colloque national en calcul des structures, CSMA, May 2007, Giens, France. hal01507584

\section{HAL Id: hal-01507584 \\ https://hal.science/hal-01507584}

Submitted on 13 Apr 2017

HAL is a multi-disciplinary open access archive for the deposit and dissemination of scientific research documents, whether they are published or not. The documents may come from teaching and research institutions in France or abroad, or from public or private research centers.
L'archive ouverte pluridisciplinaire HAL, est destinée au dépôt et à la diffusion de documents scientifiques de niveau recherche, publiés ou non, émanant des établissements d'enseignement et de recherche français ou étrangers, des laboratoires publics ou privés. 


\title{
A thermo-hydraulic numerical model to study spot laser welding
}

\author{
Marc Medale* — Charline Xhaard** — Rémy Fabbro*** \\ * Polytech' Marseille, Lab. IUSTI, UMR 6595 CNRS - Université de Provence \\ Technopole de Château-Gombert, 5 rue Enrico Fermi \\ 13453 Marseille Cedex 13 \\ ** CEA, Centre de Valduc, DAM/DFTN \\ 21120 IS sur TILLE
}

*** CLFA/LALP, UPR CNRS 1578, 16 bis avenue Prieur de la Côte d'Or

94114 Arcueil Cedex

Marc.Medale@polytech.univ-mrs.fr

RÉSUMÉ. Un modèle numérique thermo-hydraulique pour l'étude du soudage laser impulsionnel. L'objectif de cette étude vise à mieux comprendre les mécanismes de base à l'origine de défauts en cours de soudage par laser impulsionnel. Dans ce but, nous avons développé un modèle numérique qui tient compte de la dynamique de creusement en mode key-hole, ainsi qu'un modèle de dépôt d'énergie incluant les effets de réflexions multiples. Plusieurs expériences ont permis de mettre en évidence divers types de défauts. Les simulations numériques de certains de ces scénarios ont été effectuées et comparées aux résultats éxpérimentaux.

ABSTRACT. The aim of this study is to better understand the basic mechanisms leading to defect occurrence in spot laser welding. For that purpose we have developed a numerical model, which takes into account the key-hole dynamics together with a dedicated energy deposition model featuring the multiple reflection effects. Many experiments have also been achieved enabling us to report several defect classes. The analysis of some of these scenarios have been performed and favourably compared to experiments.

MOTS-CLÉS: Mécanique des Fluides Numérique ; Soudage laser impulsionnel ; Surface libre et mobile.

KEYWORDS: Computational Fluid Mechanics; Spot laser welding; Free and moving interface. 


\section{Introduction}

Compared to other welding processes spot laser welding offers several advantages in industrial manufacturing. Indeed, localized temperature gradients require weaker global heating, so one could consequently expect lower workpiece distortions. Therefore spot laser welding processes are well suited to problems in which the allowed Affected Heat Zone is required to remain as small as possible in the vicinity of the welded joins. Unfortunately, the operating parameters leading to defect-free welded joins are difficult to obtain, owing to a relatively poor understanding of the problem. Consequently, unsafe welded joins are repeatedly encountered, polluted by micro or macro pore defects.

In order to better understand why and how these defects occur, both experimental and numerical approaches have been undertaken (Girard et al., 2000). From the computational point of view, at least three major types of difficulties have to be overcome to design robust and accurate numerical models well suited to the spot-laser-welding class of problems: i) The laser-beam energy deposition onto a moving and highly deforming interface (keyhole) requires dedicated numerical models. Several models based on Fresnel's laws have been developed to account for the local energy concentration over the keyhole (Fabbro et al., 2000 ; Amara et al., 2002).; ii) The multiphase problem (solid-liquid-gas) is not straightforward to deal with, especially for alloys made up of several metals. Few authors have proposed to solve the incompressible Navier Stokes equations in all phases (solid, liquid and gas) (Ganesh et al., 1997). Nonetheless, the relevance of such models becomes questionable in the gas phase, where the Mach number could reach values up to 0.5; iii) The algebraic system resulting from the discretization of this class of problems is very stiff (ill-conditioned) from the numerical point of view, owing to the strong material and geometrical coupling. It remains up-to-now computationally expensive to solve. For these reasons analytical and semi-analytical approaches are still widely used in the keyhole dynamics models (Semak et al., 1999 ; Solana et al., 1999), as far as three-dimensional effects could not be neglected.

\section{Physical and numerical models}

The present model has been designed to study the dynamics of a single-laserpulse over a thin metal plate. It is assumed both the axial-symmetry condition; no ionization of the metallic vapours and shield gas throughout the whole transient study, together with no beam diffusion inside the vapours. Furthermore, the coupled fluid flow and heat transfer model is focused on the condensed phases (solid and liquid), whereas the dispersed ones (metallic vapours and shield gas) have been modelled in the simplest way, so that they enter the model as boundary conditions of the former model. 
The numerical model is built in the finite element framework and takes advantage of the segregated approach, which. consists in splitting the whole problem into subproblems. The four stages considered in our model are the following: i) the laser-beam energy deposition; ii) the heat transfer in the whole computational domain; iii) the fluid flow in the liquid phase, if any; iiii) domain update to satisfy the mass conservation. The resulting solution algorithm consists in consecutively solving these four stages at each time step of the whole transient (Medale et al., 2004).

\subsection{Laser-beam energy deposition model}

Let us discretize the laser-beam into concentric annulii, and based on Fresnel's laws one determines its optical path throughout multiple reflections into the keyhole. Along the optical path, in each ray interaction with the condensed matter, a part of the incident optical power is transmitted, whereas the remaining is reflected with an angle equal to the incidence one. Therefore, the transmitted power density only depends on both the incidence angle and the local temperature at the incident location. It acts in our numerical model as an applied heat flux, which represents the boundary source term for the heat transfer model.

\subsection{Heat transfer model}

The macroscopic model dedicated to the condensed phases is derived from the two-phase model and the energy conservation equation is written in enthalpy formulation. As the computational domain has moving and deforming boundaries, the conservation equations are written in an Arbitrary-Lagrangian-Eulerian formulation. The thermal boundary conditions can be splitted into four parts. The first one is associated with the axial-symmetry condition (adiabatic condition along the symmetry axis); the second one is the applied heat flux associated with the laser beam interaction ; the third boundary condition models the rate of thermal energy devoted to vaporization or condensation, if any. It is accounted for in our model as a boundary condition over the liquid-vapor interface, as follows: the vaporization rate is drawn from the mass balance across the liquid-vapor interface. Finally, the forth thermal boundary condition is associated with the radiative and convective heat transfer over the other boundaries of the condensed phase domain.

\subsection{Fluid flow model}

The heat transfer in the condensed phases is significantly dominated by advection in the melted pool, where the liquid metal flow is modeled as an incompressible fluid flow. Nevertheless the basic Navier-Stokes equations should be slightly modified to account for the inter-dendrites fluid flow at the macroscopic scale. The first constitutive law used to close the preceding set of equations is that of Newtonian fluid. Secondly, the Boussinesq approximation is used to take into account buoyancy in the incompressible fluid flow model. Finally, a source term has been selectively introduced in the mushy zone to model at the macroscopic scale the 
fluid flow which takes place at microscopic scale close to solid-liquid interface, according to a Darcy-like flow in a porous media. The most important interactions between the gas phase and the liquid phase can be attributed to: i) the recoil pressure associated with the evaporation process; ii) the shear stress induced by the high velocity difference between dispersed phase and the liquid metal flow in the key hole; iii) surface tension effects (capillary forces owing to pressure difference across the interface, and thermo-capillary forces over the interface induced by surface tension gradients).

\subsection{Computational domain update - Mesh adaption model}

As the computational domain is restricted to the condensed matter (solid and liquid phases), it evolves and deforms in the course of time. So, to prevent from mesh distorsion responsible for poor solution accuracy, we supplement our numerical model with the solution at each time step of a steady pseudo-elastic problem for the mesh (Rabier et al, 2003). It is formulated in nodal mesh displacement variables in order to explicitly satisfy a kinematic boundary condition all over the fluid flow domain boundary. This kinematic condition states a vanishing normal component of the relative velocity between the liquid fluid flow and the mesh along the boundaries.

\section{Analysis}

We consider a single laser pulse carried out in the middle of a thin metal sheet, to satisfy the axial-symmetry condition. The delivered laser beam power is considered constant $(\mathrm{P}=1500 \mathrm{~W})$ throughout the $10 \mathrm{~ms}$ laser pulse. It is carried by an optical fibber and its spatial distribution over the metal sheet is assumed to be a $600 \mu \mathrm{m}$ diameter top hat at the focal point. The TA6V plate (aluminium alloy) has been modeled with the following physical properties provided in table 1.

\begin{tabular}{|c|c|}
\hline Melting temperature $(\mathrm{K})$ & 1923 \\
\hline Vaporization temperature $(\mathrm{K})$ & 3591 \\
\hline Liquid density $\left(\mathrm{Kg} \cdot \mathrm{m}^{-3}\right)$ & 4110 \\
\hline Specific heat $\left(\mathrm{J} \cdot \mathrm{kg}^{-1} \cdot \mathrm{K}^{-1}\right)$ & 743 \\
\hline Thermal conductivity $\left(\mathrm{W} \cdot \mathrm{m}^{-1} \cdot \mathrm{K}^{-1}\right)$ & 35 \\
\hline Surface tension coefficient $\left(\mathrm{N} \cdot \mathrm{m}^{-1}\right)$ & 1.6 \\
\hline Thermal coef. surface tension $\left(\mathrm{N} \cdot \mathrm{m}^{-1} \cdot \mathrm{K}^{-1}\right)$ & $310^{-4}$ \\
\hline Viscosity $(\mathrm{Pa} . \mathrm{s})$ & $3410^{-4}$ \\
\hline Liquid-gas latent enthalpy $\left(\mathrm{J} \cdot \mathrm{kg}^{-1}\right)$ & $8.810^{6}$ \\
\hline Solid-liquid latent enthalpy $\left(\mathrm{J} \cdot \mathrm{kg}^{-1}\right)$ & $0.410^{6}$ \\
\hline
\end{tabular}

Table 1. Physical properties used for the TA6V alloy at $1923 \mathrm{~K}$. 
The finite element model has been first validated in simplified configurations, so, the present study aims to validate the energy deposition model in a dynamically deforming keyhole where multiple reflections take place. As the free surface deforms to a large extent (keyhole) during the laser pulse, the laser energy deposition becomes of first concern, especially when multiple reflections occur in the keyhole. The physical domain is $3 \mathrm{~mm}$ thick (metal sheet thickness), and $1 \mathrm{~mm}$ wide, initially at ambiant room temperature $T_{0}=300 \mathrm{~K}$. The mesh used in the present computations is made up of $75 \times 150$ bi-quadratic quadrilateral finite elements (Q9), non-uniformly distributed in the radial and axial directions, respectively. A constant time increment of $10^{-2} \mathrm{~ms}$ has been used, so the computation of the whole laser pulse requires 1000 time steps.

The recoil pressure applied onto the free surface induces a fast drilling of the keyhole. The computations faithfuly reproduce this behaviour, as shown in figures 1 for $\mathrm{t}=7.5 \mathrm{~ms}$. As the keyhole becomes deeper and deeper the number of laser-rays reflections increases significantly, and the optical path get more and more complex along the keyhole. The multiple reflections inside the highly deformed keyhole result in a noticeable power intensity focus over the keyhole tip. Indeed the global absorbtivity coefficient raises from roughly $50 \%$ at the beginning of the laser pulse up to $80 \%$ as soon as the keyhole is deep enough to trap most of the reflected rays. The finite element mesh adaption technique performs well to deal with the moving boundary problem in such a highly deformed computational domain, resulting in a fairly good accuracy over the whole computations.
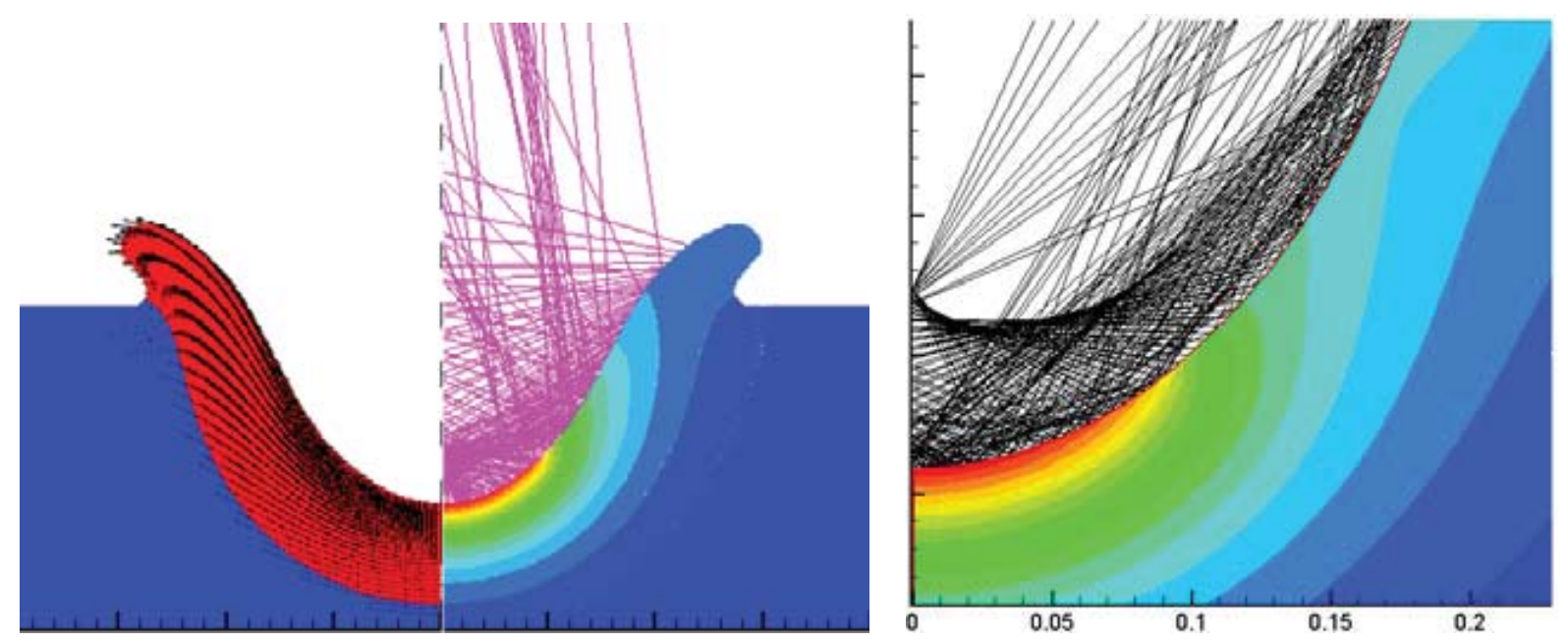

Fig. 1. Velocity field in the liquid metal (left), reflected rays at the liquid-gas interface and thermal field (right) at $t=7.5 \mathrm{~ms}$. 


\section{Conclusion}

The numerical model we have developed to study the dynamics of a single laser pulse acting on a thin metal sheet is expected to provide us with a better understanding of the basic mechanisms that could be responsible for numerous defects in industrial spot laser welding processes. It is focussed on the condensed phases (solid and liquid), but take into account the dispersed phase (vapors and shield gas) in a simplified manner. It is made up of four main stages: the laser energy deposition, the heat transfer in computational domain, the fluid flow in the liquid phase, if any, and finally a computational domain and mesh update to account for the total mass conservation and large distorsion of the liquid-gas interface (keyhole). The present study deals with an intermediate level validation whose objective was the test and verification of the energy deposition model on a dynamically deforming keyhole where multiple reflections take place. As the free surface shape evolves continually during the laser pulse, the ray paths (determined by Fresnel's law) become of first concern to accurately compute the laser energy deposition, especially when multiple reflections occur in the keyhole.

\section{References}

Amara E., Bendib A., " Modelling of vapour flow in deep penetration laser welding ", $J$. Phys. D: Appl. Phys. 35, 2002, p. 272-280.

Fabbro R., Chouf K., « Keyhole modelling during laser welding », J. Phys. D: Appl. Phys. 87, 2000, p. 4075-4083.

Ganesh R.K., Faghri A., Hahn Y., « A generalized thermal modelling for laser drilling process - I. Mathematical modelling and numerical methodology », J. Heat Mass Transfer 40, 1997, p. 3351-3373.

Girard K., Jouvard J.M., Boquillon J., Bouilly P., Naudy P., Proc. SPIE Conf. (Bellingham, SPIE) 3888, 2000, p. 418-28.

Medale M., Rabier S., Xhaard C., « A thermo-hydraulic numerical model for high energy welding processes », Rev. Eur. Elements Finis 13, 2004, p. 207-229.

Rabier S., Medale M., " Computation of free surface flows with a projection FEM in a moving mesh framework », Comput. Methods Appl. Mech. Engrg. 192, 2003, p. 47034721.

Semak W., Bragg W.D., Damkroger B., Kempkas S., « Temporal evolution of the temperature field in the beam interaction zone during laser-material processing ", J. Phys. D: Appl. Phys. 32, 1999, p. 1819-1825.

Solana P., Kapadia P., Dowden J.M., Marsden P.J., « An analytical model for laser drilling of metals with absorption within the vapour », J. Phys. D: Appl. Phys. 32, 1999, p. 942-952. 